\title{
FATORES ASSOCIADOS A SÍNDROME DE BURNOUT: UMA REVISÃO SISTEMÁTICA DA LITERATURA
}

\author{
FACTORS ASSOCIATED WITH BURNOUT SYNDROME: A \\ SYSTEMATIC REVIEW OF THE LITERATURE
}

Danielle Figueiredo Patrício ${ }^{1}$
Rafaela Ramos Dantas
Andrezza Oliveira Barros

RESUMO: OBJETIVO: Identificar estudos empíricos que associem burnout com outros fatores ocasionados pelo trabalho e analisar o delineamento de pesquisa desenvolvido. MÉTODOS: Foi realizada uma revisão integrativa (RI) da literatura nacional com abordagem retrospectiva, no período de 2008 a 2018. Disponíveis nas bases SciELO - Scientific Eletronic Library e Biblioteca Virtual em Saúde - BVS, por serem referências para o campo de pesquisas da Saúde. Desenvolveu-se em seis etapas recomendadas: identificação do tema ou questão de pesquisa; estabelecimento de critérios para inclusão e exclusão de estudos; definição das informações a serem extraídas dos estudos selecionados/categorização dos estudos; avaliação dos estudos incluídos; interpretação dos resultados e apresentação da síntese do conhecimento, os estudos foram classificados com base no nível de evidência. RESULTADOS: Foram selecionados onze estudos, que atenderam aos critérios de inclusão/exclusão, dez são artigos publicados em periódicos e uma dissertação. Observa-se com os resultados, que as profissões pesquisadas são essencialmente os profissionais de saúde e professores, e que todos os estudos desta revisão utilizaram as versões do instrumento Maslach Burnout Inventory (MBI) para avaliar burnout. CONCLUSÃO: Burnout está associado a diversos fatores individuais, sociais, psicológicos e ambientais no trabalho, esta informação trata-se de um alerta tanto para os trabalhadores, como para os gestores, sejam eles de instituições públicas ou privadas. Existe uma via de mão dupla, pois por parte, os trabalhadores devem possuir mecanismos próprios de defesa e as organizações devem pautar-se de melhorias e novas políticas públicas em busca da garantia da prestação de serviço com qualidade.

\footnotetext{
${ }^{1}$ Mestre em Psicologia da Saúde e Graduada em Enfermagem pela Universidade Estadual da Paraíba (UEPB), Professora do Departamento de Enfermagem da UEPB.

${ }^{2}$ Mestre em Saúde da Criança e Adolescente pela UFPE e Graduada pela Universidade Estadual da Paraíba (UEPB), Professora do Departamento de Enfermagem da UEPB.

${ }^{3}$ Especialista em Urgência e Emergência e Graduada pela UNIFACISA, Professora do Departamento de Enfemagem da UEPB.
} 
Palavras chave: burnout; esgotamento profissional; síndrome de burnout; síndrome de esgotamento profissional. 


\section{INTRODUÇÃO}

De acordo com a abordagem psicossociológica, burnout é uma síndrome que surge como uma resposta à tensão emocional crônica no trabalho, sendo formada por três componentes interdependentes: Exaustão Emocional, Despersonalização e reduzida Realização Profissional. A Exaustão Emocional, (EE) representa o componente individual do estresse no burnout. Caracteriza-se pelo esgotamento de energia física e psíquica do profissional para lidar com situações estressoras e altas exigências no trabalho. A Despersonalização (DP) representa o componente interpessoal. Manifesta-se por atitudes de cinismo e sentimentos negativos, endurecimento afetivo e desumanização para com as pessoas no ambiente de trabalho. A reduzida Realização Profissional (rRP) representa o componente de autoavaliação. Sendo caracteriza pela tendência dos profissionais se autoavaliarem negativamente, sentindo-se profissionalmente frustrados e insatisfeitos com o desempenho no trabalho. Essa sensação de descontentamento é acentuada pela falta de recursos no trabalho, de apoio social e de oportunidades de desenvolvimento profissional (GIL-MONTE, 2003; MASLACH, 2009).

Burnout é uma experiência individual e contextual relacionada ao trabalho. Seus sintomas tendem a se manifestar em pessoas normais que não sofrem de uma psicopatologia anterior ou de uma doença orgânica identificável (MASLACH, LEITER, 2008). As causas do Burnout não estão localizadas em traços permanentes das pessoas, mas em certos fatores situacionais e sociais específicos que podem ser influenciados e modificados, contudo, burnout pode acarretar outros problemas psicológicos. Nos primeiros estudos, Maslach (1976) acreditava que tal fenômeno se desenvolvia exclusivamente em profissionais ligados a assistência, porque a natureza de seu trabalho lhes exigia manter contato direto e frequente com outras pessoas, acarretando grande dispêndio emocional. Contudo, na medida que as pesquisas avançavam, foram identificados sintomas de burnout em muitos grupos profissionais que, até então, não eram considerados populações de risco. Diante 
disso, Maslach e Jackson (1981) e Maslach e Leiter (2008) evidenciam que a síndrome não se restringe a profissões assistenciais, sendo este um fenômeno que afeta praticamente todas as profissões, já que a maioria possui algum tipo de contato interpessoal, quer seja com clientes, consumidores, colegas, supervisores, a partir disso surgindo diversos estudos envolvendo diferentes grupos profissionais. Segundo Trigo, Teng e Hallak (2007), os dados encontrados sobre a síndrome de burnout ainda são incertos com relação à prevalência e a comorbidade com transtornos psiquiátricos.

Maslach, Schaufeli e Leiter (2001) dividem a história sobre os estudos de burnout em duas fases: a primeira, a partir de 1974, caracterizada por pesquisas exploratórias, qualitativas, com a utilização de entrevistas, estudos de caso e observações, tiveram como principal contribuição a compreensão e descrição do fenômeno. A segunda fase, chamada de empírica, inicia-se nos anos 1980 e apresenta como principal característica a sistematização das pesquisas com a utilização de instrumentos padronizados, como o Maslach Burnout Inventory - MBI, desenvolvido por Maslach e Jackson (1981) que passou a ser muito difundido e o mais utilizado em pesquisas até hoje (GARCIA, BENEVIDES PEREIRA, 2003; GILMONTE, 2003). A partir da década de 1990, dando sequência à fase empírica, o conceito de burnout, até então restrito a profissões humanitárias, se estende a outras profissões. Além disso, as pesquisas dispunham de metodologias e ferramentas estatísticas mais sofisticadas que permitiam estudos com grande número de sujeitos. Também nessa fase começam os estudos longitudinais (MASLACH, SCHAUFELI, LEITER, 2001).

Considerando que a síndrome de burnout é um assunto amplamente discutido e estudado dentro do campo da saúde do trabalhador, visto que afeta diferentes profissões e possivelmente acarreta outros distúrbios, surgiu o interesse de saber quais os distúrbios que a síndrome está sendo associada. Com isso o objetivo deste estudo é identificar de acordo com a literatura estudos empíricos que associem burnout com outros fatores ocasionados pelo trabalho e analisar o delineamento de pesquisa desenvolvido. 


\section{MÉTODO}

Para alcançar o objetivo, foi realizada uma revisão integrativa $(\mathrm{RI})$ da literatura nacional com abordagem retrospectiva em portais virtuais que disponibilizam coleções selecionadas de periódicos científicos. Desenvolveu-se em seis etapas recomendadas por Mendes, Silveira e Galvão (2008): identificação do tema ou questão de pesquisa; estabelecimento de critérios para inclusão e exclusão de estudos; definição das informações a serem extraídas dos estudos selecionados/categorização dos estudos; avaliação dos estudos incluídos; interpretação dos resultados e apresentação da síntese do conhecimento.

Para tanto a questão norteadora desta pesquisa é: a quais fatores a síndrome de burnout vem sendo associada nas pesquisas de campo que analisam a saúde do trabalhador? As palavras-chave utilizadas foram selecionadas a partir dos Descritores em Ciências da Saúde (DeCS), e seus sinônimos foram combinados de diferentes formas, sendo estes: burnout; esgotamento profissional; síndrome de burnout; síndrome de esgotamento profissional; estafa profissional; exaustão profissional; esgotamento emocional; esgotamento psíquico; desgaste profissional; exaustão emocional e física. A busca foi realizada por dois revisores de maneira independente utilizando os operadores booleanos OR e/ou AND, após diferentes combinações, definiu-se os seguintes descritores para a busca: burnout OR esgotamento profissional AND fatores associados. A pesquisa seguiu as recomendações metodológicas da declaração PRISMA (Preferred Reporting Items for Systematic Reviews and Meta-Analyses) para trabalhos de revisão sistemática (MOHER, LIBERATI, TETZLAFF, ALTMAN, 2009).

Dentre os portais virtuais disponíveis, foram selecionados dois de referência nacional e de acesso internacional: a) SciELO - Scientific Eletronic Library e b) Biblioteca Virtual em Saúde - BVS, por serem referências para o campo de pesquisas da Saúde, em busca de analisar a produção científica acerca da temática proposta dentro do contexto geográfico e cultural no qual estamos inseridos. Vale que ressaltar que, apesar destes portais oferecerem grande representatividade na 
divulgação de trabalhos, não representa a totalidade da produção acadêmica e científica nacional.

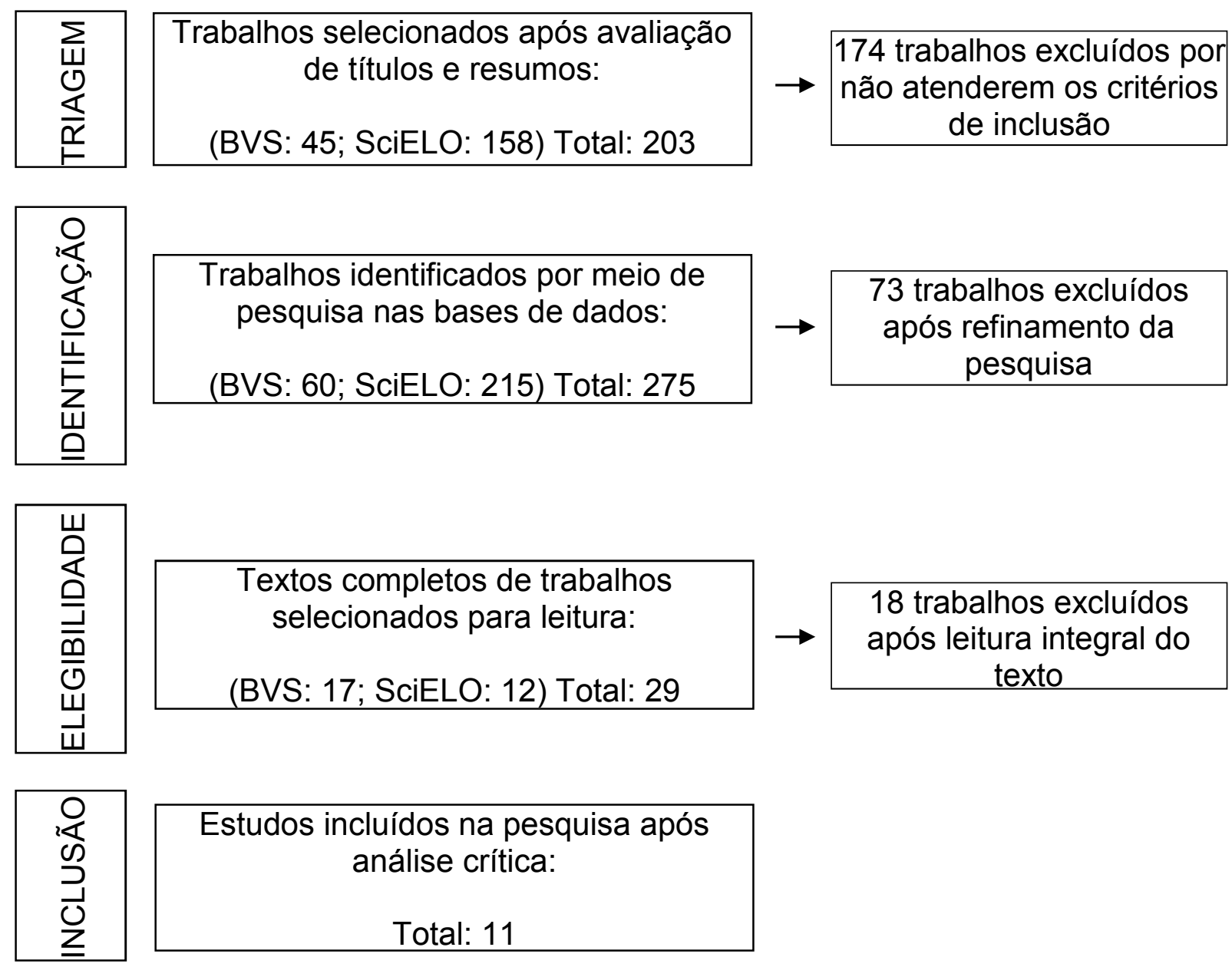

Figura 1 - Representação esquemática dos métodos de seleção dos estudos, adaptada de acordo com o PRISMA Flow Diagram.

Este levantamento foi realizado durante o período de desenvolvimento da discussão de uma dissertação que abordou o seguinte construto: burnout e depressão em profissionais de enfermagem, também com a pretensão de identificar lacunas nos estudos associativos sobre burnout, direcionando futuras pesquisas. A pesquisa buscou artigos publicados nos últimos dez anos (2008 - 2018), considerouse este período pois considerou-se um período válido para levantamento 
bibliográfico para discussão dos resultados da dissertação em questão. Os artigos encontrados foram submetidos a uma leitura criteriosa dos títulos, resumos e palavras-chave de todas as publicações completas. A seleção dos estudos analisados ocorreu a partir dos seguintes critérios de inclusão: abordar a temática em estudo; constar nas bases de dados selecionadas; texto disponível na íntegra; ser redigido ou traduzido em português; e ter sido publicado no período de 2008 a 2018. Os critérios de exclusão foram: textos incompletos ou com acesso indisponível; repetição de um mesmo artigo em mais de uma base de dados; falta de relação com o objeto de estudo; e artigos de revisão ou literatura cinza.

Após a seleção dos estudos, efetuou-se o processo de análise dos estudos com base no delineamento da pesquisa, extração e análise dos dados. Inicialmente os estudos foram caracterizados (tipo de material, autores, título, ano de publicação, amostra e objetivos), classificados com base no nível de evidência: Nível I - as evidências provêm de revisão sistemática ou metanálise de todos os ensaios clínicos relevantes randomizados controlados ou originam-se de diretrizes clínicas baseadas em revisões sistemáticas de ensaios clínicos randomizados controlados; Nível II evidências derivadas de, pelo menos, um ensaio clínico randomizado controlado bem delineado; Nível III - evidências obtidas de ensaios clínicos bem delineados sem randomização; Nível IV - evidências provenientes de estudos de coorte e de caso-controle bem delineados; Nível V - evidências originárias de revisão sistemática de estudos descritivos e qualitativos; Nível VI - evidências derivadas de um único estudo descritivo ou qualitativo; Nível VII - evidências oriundas de opinião de autoridades e/ou relatório de comitês de especialistas (MELNYK, FINEOUTOVERHOLT, 2005), em seguida é descrito o âmbito do estudo, o desenho metodológico (tipo de pesquisa, instrumentos utilizados, variáveis estudadas e tipo de análises), estes dados estão apresentados em tabelas. Por fim os estudos são categorizados para análise e interpretação dos resultados. 


\section{RESULTADOS}

Nesta pesquisa bibliográfica foram selecionados onze estudos enumerados aleatoriamente (tabela 1 e 2), que atenderam aos critérios de inclusão/exclusão previamente estabelecidos e apresentados, dos quais, dez são artigos publicados em periódicos e uma dissertação, disponíveis nas duas bases de dados selecionadas para o estudo. O período definido para seleção foi entre 2008 e 2018, praticamente em todos os anos houve publicação sobre o tema escolhido, excluindo apenas 2009 e 2016, mostrando que burnout apesar de não ser um tema recente, continua sendo bastante difundido no meio acadêmico, por ser um tema relevante e consequentemente atualizado, considerando as transformações ocorridas no mundo do trabalho.

Observa-se com os resultados dos estudos selecionados, que as profissões pesquisadas são essencialmente os profissionais de saúde e professores, corroborando com dados da Organização Internacional do Trabalho (OIT), os quais afirmam que estas profissões continuam sendo as mais acometidas por burnout isso em âmbito mundial, por isso, estudos com esses dois grupos são importantes para se possam avançar em medidas interventivas em busca de alternativas preventivas e combativas (CARLOTTO, 2010; GIL-MONTE, 2008). Vale ressaltar, que foram incluídos apenas artigos publicados em português, o que explica o fato de serem publicações exclusivamente nacionais, com exceção de uma que compara os dados entre profissionais de saúde de Porto Alegre no Brasil e na cidade do Porto em Portugal (DIAS, QUEIRÓS, CARLOTTO, 2010), o que não possibilita apresentar dados a respeito das publicações internacionais neste período sobre os fatores associados a burnout.

Todos os estudos foram classificados com o nível de evidência VI (evidências derivadas de um único estudo descritivo ou qualitativo), pois nos critérios de exclusão os artigos de revisão não estavam contemplados. Todos os estudos desta revisão utilizaram as versões do instrumento Maslach Burnout Inventory (MBI) para avaliar burnout, que é um instrumento psicométrico validado em todo mundo, com 
bons coeficientes de alfa de Cronbach (acima de 0,75) em todas as validações, por isso desde sua criação pela psicóloga social Christina Maslach em 1986 é o instrumento mais utilizado nas pesquisas científicas que envolvem o construto burnout, também é considerado o mais eficaz para a mensuração da síndrome (SÁ, MARTINS-SILVA, FUNCHAL, 2014; SALVIANO, 2016).

Nos estudos selecionados o âmbito das pesquisas foi predominantemente em ambientes laborais públicos, o que permite visualizar uma lacuna em pesquisas envolvendo burnout em locais privados. Com a leitura dos objetivos apresentados na tabela 2, é possível perceber que existe uma preocupação no meio acadêmico em descobrir a gênese da síndrome de burnout, através dos fatores associados que descrevem quais aspectos ambientais, físicos, sociais e psicológicos que levam o indivíduo trabalhador a adoecer, desenvolvendo a síndrome acarretando a diminuição da qualidade do serviço prestado, como é o caso dos profissionais de saúde e professores.

Tabela 1. Apresentação dos resultados da revisão.

\begin{tabular}{|c|c|c|c|c|c|c|c|}
\hline $\mathrm{N}$ & $\begin{array}{l}\text { Tipo de } \\
\text { material }\end{array}$ & Autores & Título & $\begin{array}{c}\text { Ano de } \\
\text { publicação }\end{array}$ & Objetivo geral & Periódico & $\begin{array}{l}\text { Nível de } \\
\text { evidência }\end{array}$ \\
\hline 1 & Artigo & Carlotto MS & $\begin{array}{c}\text { Síndrome de } \\
\text { Burnout em } \\
\text { Professores: } \\
\text { Prevalência e } \\
\text { Fatores } \\
\text { Associados }\end{array}$ & 2011 & $\begin{array}{c}\text { Identificar a } \\
\text { prevalência da } \\
\text { Síndrome de } \\
\text { Burnout em } 882 \\
\text { professores de } \\
\text { escolas da região } \\
\text { metropolitana de } \\
\text { Porto Alegre-RS }\end{array}$ & $\begin{array}{c}\text { Psicologia: } \\
\text { Teoria e } \\
\text { Pesquisa }\end{array}$ & VI \\
\hline 2 & Artigo & $\begin{array}{l}\text { Andolhe R, } \\
\text { Barbosa RL, } \\
\text { Oliveira EM, } \\
\text { Costa ALS, } \\
\text { Padilha KG }\end{array}$ & $\begin{array}{c}\text { Estresse, } \\
\text { coping e } \\
\text { burnout da } \\
\text { Equipe de } \\
\text { Enfermagem } \\
\text { de Unidades de } \\
\text { Terapia } \\
\text { Intensiva: } \\
\text { fatores } \\
\text { associados }\end{array}$ & (1) & $\begin{array}{l}\text { Verificar os níveis } \\
\text { de estresse, } \\
\text { estratégias de } \\
\text { coping e burnout } \\
\text { dos profissionais } \\
\text { que atuam em UTI e } \\
\text { sua associação com } \\
\text { os fatores } \\
\text { biossociais e de } \\
\text { trabalho. }\end{array}$ & $\begin{array}{c}\text { Revista } \\
\text { Escola de } \\
\text { Enfermage } \\
\text { m da USP }\end{array}$ & VI \\
\hline 3 & Artigo & $\begin{array}{l}\text { Meneghini F, } \\
\text { Paz AA, Lautert } \\
\text { L }\end{array}$ & $\begin{array}{c}\text { Fatores } \\
\text { ocupacionais } \\
\text { associados aos } \\
\text { componentes } \\
\text { da síndrome de } \\
\text { burnout em } \\
\text { trabalhadores } \\
\text { de enfermagem }\end{array}$ & 2011 & $\begin{array}{l}\text { Identificar os fatores } \\
\text { ocupacionais } \\
\text { associados com os } \\
\text { três componentes } \\
\text { da Síndrome de } \\
\text { Burnout em } \\
\text { trabalhadores de } \\
\text { enfermagem que }\end{array}$ & $\begin{array}{c}\text { Texto } \\
\text { Contexto } \\
\text { Enfermage } \\
\text { m }\end{array}$ & VI \\
\hline
\end{tabular}




\begin{tabular}{|c|c|c|c|c|c|c|c|}
\hline & & & & & $\begin{array}{l}\text { atuam em } \\
\text { assistência } \\
\text { hospitalar. }\end{array}$ & & \\
\hline 4 & Artigo & $\begin{array}{c}\text { Galindo RH, } \\
\text { Feliciano KVO, } \\
\text { Lima RAS, } \\
\text { Souza Al }\end{array}$ & $\begin{array}{l}\text { Síndrome de } \\
\text { Burnout entre } \\
\text { enfermeiros de } \\
\text { um hospital } \\
\text { geral da cidade } \\
\text { do Recife }\end{array}$ & 2012 & $\begin{array}{c}\text { Identificar a } \\
\text { ocorrência de } \\
\text { burnout, e alguns } \\
\text { fatores sócio- } \\
\text { demográficos e das } \\
\text { condições do } \\
\text { trabalho que } \\
\text { lhes são associados } \\
\text { entre enfermeiros }\end{array}$ & $\begin{array}{c}\text { Revista } \\
\text { Escola de } \\
\text { Enfermage } \\
\text { m da USP }\end{array}$ & VI \\
\hline 5 & Artigo & $\begin{array}{l}\text { Lima RAS, } \\
\text { Souza AI, } \\
\text { Galindo RH, } \\
\text { Feliciano } \\
\text { KVO }\end{array}$ & $\begin{array}{l}\text { Vulnerabilidade } \\
\text { ao burnout } \\
\text { entre médicos } \\
\text { de hospital } \\
\text { público do } \\
\text { Recife }\end{array}$ & 2013 & $\begin{array}{c}\text { Identificar a } \\
\text { vulnerabilidade de } \\
\text { médicos do SUS ao } \\
\text { burnout }\end{array}$ & $\begin{array}{l}\text { Ciência \& } \\
\text { Saúde } \\
\text { Coletiva }\end{array}$ & VI \\
\hline 6 & Artigo & $\begin{array}{c}\text { Silva SCPS et } \\
\text { al }\end{array}$ & $\begin{array}{l}\text { A síndrome de } \\
\text { burnout em } \\
\text { profissionais da } \\
\text { rede de } \\
\text { atenção } \\
\text { Primária à } \\
\text { Saúde de } \\
\text { Aracaju, Brasil }\end{array}$ & 2015 & $\begin{array}{c}\text { Avaliar a } \\
\text { prevalência de } \\
\text { Síndrome de } \\
\text { Burnout e fatores } \\
\text { associados em } \\
\text { profissionais de } \\
\text { nível superior } \\
\text { vinculados à Rede } \\
\text { de Atenção Primária } \\
\text { à Saúde (REAP) do } \\
\text { município de } \\
\text { Aracaju/SE. }\end{array}$ & $\begin{array}{c}\text { Ciência \& } \\
\text { Saúde } \\
\text { Coletiva }\end{array}$ & VI \\
\hline 7 & Artigo & $\begin{array}{l}\text { Martins LF et } \\
\text { al. }\end{array}$ & $\begin{array}{l}\text { Esgotamento } \\
\text { entre } \\
\text { profissionais da } \\
\text { atenção } \\
\text { Primária à } \\
\text { Saúde }\end{array}$ & 2014 & $\begin{array}{c}\text { Avaliar o } \\
\text { esgotamento } \\
\text { profissional entre } \\
\text { trabalhadores da } \\
\text { APS em três } \\
\text { municípios de } \\
\text { pequeno porte da } \\
\text { Zona da Mata } \\
\text { Mineira. }\end{array}$ & $\begin{array}{c}\text { Ciência \& } \\
\text { Saúde } \\
\text { Coletiva }\end{array}$ & VI \\
\hline 8 & Artigo & $\begin{array}{l}\text { Dias S, Queirós } \\
\text { C, Carlotto MS }\end{array}$ & $\begin{array}{l}\text { Síndrome de } \\
\text { burnout e } \\
\text { fatores } \\
\text { associados em } \\
\text { profissionais da } \\
\text { área da saúde: } \\
\text { um estudo } \\
\text { comparativo } \\
\text { entre Brasil e } \\
\text { Portugal }\end{array}$ & 2010 & $\begin{array}{c}\text { Comparar a } \\
\text { prevalência e os } \\
\text { fatores associados à } \\
\text { síndrome de } \\
\text { burnout de uma } \\
\text { amostra de } 224 \\
\text { profissionais da } \\
\text { saúde, } 112 \\
\text { brasileiros e } 112 \\
\text { portugueses. }\end{array}$ & Aletheia & VI \\
\hline 9 & Artigo & $\begin{array}{c}\text { Silva, A. F. et } \\
\text { al. }\end{array}$ & $\begin{array}{l}\text { Fatores que } \\
\text { prevalecem ao } \\
\text { esgotamento } \\
\text { profissional em } \\
\text { professores }\end{array}$ & 2017 & $\begin{array}{c}\text { Verificar a } \\
\text { prevalência da } \\
\text { Síndrome de } \\
\text { Burnout (SB) em } \\
\text { professores da rede } \\
\text { pública dos Ensinos } \\
\text { Infantil, } \\
\text { Fundamental e } \\
\text { Médio e analisar a }\end{array}$ & $\begin{array}{l}\text { Cadernos } \\
\text { Brasileiros } \\
\text { de Terapia } \\
\text { Ocupacional }\end{array}$ & VI \\
\hline
\end{tabular}




\begin{tabular}{|c|c|c|c|c|c|c|}
\hline & & & & $\begin{array}{l}\text { associação entre } \\
\text { SB e fatores } \\
\text { associados. }\end{array}$ & & \\
\hline 10 Dissertação & Soares RS & $\begin{array}{c}\text { Burnout e } \\
\text { fatores } \\
\text { associados } \\
\text { entre } \\
\text { profissionais de } \\
\text { enfermagem de } \\
\text { hospital } \\
\text { municipal no } \\
\text { Rio de Janeiro }\end{array}$ & 2018 & $\begin{array}{l}\text { Descrever a } \\
\text { prevalência e } \\
\text { possíveis fatores } \\
\text { associados à } \\
\text { síndrome de } \\
\text { burnout entre } \\
\text { profissionais de } \\
\text { enfermagem de } \\
\text { setores fechados. }\end{array}$ & $\begin{array}{l}\text { Universidad } \\
\text { e Federal } \\
\text { Fluminense }\end{array}$ & $\mathrm{VI}$ \\
\hline Artigo & $\begin{array}{l}\text { Barros DS, } \\
\text { Tironi MOS, } \\
\text { Nascimento } \\
\text { Sobrinho CL, }\end{array}$ & $\begin{array}{c}\text { Médicos } \\
\text { plantonistas de } \\
\text { unidade de } \\
\text { terapia } \\
\text { intensiva: perfil } \\
\text { sócio- } \\
\text { demográfico, } \\
\text { condições de } \\
\text { trabalho e } \\
\text { fatores } \\
\text { associados à } \\
\text { síndrome de } \\
\text { burnout } \\
\end{array}$ & 2008 & $\begin{array}{l}\text { Descrever o perfil } \\
\text { de médicos } \\
\text { plantonistas de } \\
\text { unidades de terapia } \\
\text { intensiva e avaliar } \\
\text { os fatores } \\
\text { associados à } \\
\text { presença de } \\
\text { síndrome de } \\
\text { Burnout nessa } \\
\text { população. }\end{array}$ & $\begin{array}{c} \\
\text { Revista } \\
\text { Brasileira de } \\
\text { Terapia } \\
\text { Intensiva }\end{array}$ & VI \\
\hline
\end{tabular}

Fonte: Elaborada pelas autoras.

Tabela 2. Apresentação dos resultados da revisão.

\begin{tabular}{|c|c|c|c|c|c|c|}
\hline $\mathrm{N}$ & Âmbito & Instrumentos & Amostra & Tipo de pesquisa & Variáveis & Análises \\
\hline 1 & $\begin{array}{c}\text { Oito escolas } \\
\text { públicas e } \\
\text { seis escolas } \\
\text { privadas de } \\
\text { Porto Alegre- } \\
\text { RS }\end{array}$ & $\begin{array}{c}\text { Variáveis } \\
\text { demográficas e } \\
\text { laborais, Maslach } \\
\text { Burnout } \\
\text { Inventory - } \\
\text { Educators } \\
\text { Survey (MBI-ED) }\end{array}$ & $\begin{array}{l}881 \\
\text { professores }\end{array}$ & $\begin{array}{c}\text { Epidemiológico } \\
\text { observacional } \\
\text { analítico de corte } \\
\text { transversal }\end{array}$ & $\begin{array}{l}\text { A prevalência } \\
\text { da síndrome } \\
\text { de Burnout e } \\
\text { sua relação } \\
\text { com fatores } \\
\text { sociodemográ } \\
\text { ficos e } \\
\text { laborais }\end{array}$ & $\begin{array}{c}\text { Descritivas, para } \\
\text { variáveis } \\
\text { quantitativas a } \\
\text { correlação de } \\
\text { Pearson, e para } \\
\text { qualitativas } t \text { de } \\
\text { student. }\end{array}$ \\
\hline 2 & $\begin{array}{l}\text { Oito UTIs de } \\
\text { um hospital } \\
\text { público da } \\
\text { cidade de } \\
\text { São Paulo }\end{array}$ & $\begin{array}{l}\text { Características } \\
\text { biossociais, } \\
\text { Escala de } \\
\text { Estresse no } \\
\text { Trabalho (EET), } \\
\text { Lista de Sinais e } \\
\text { Sintomas de } \\
\text { Estresse (LSS), } \\
\text { Escala de } \\
\text { Coping } \\
\text { Ocupacional } \\
\text { (ECO), Maslach } \\
\text { Burnout } \\
\text { Inventory - } \\
\text { Human Services } \\
\text { Survey (MBI - } \\
\text { HSS) }\end{array}$ & $\begin{array}{l}344 \\
\text { profissionais } \\
\text { deenfermage } \\
\mathrm{m}\end{array}$ & $\begin{array}{l}\text { Observacional, } \\
\text { transversal }\end{array}$ & $\begin{array}{l}\text { Os níveis de } \\
\text { estresse, } \\
\text { estratégias de } \\
\text { coping e } \\
\text { burnout e sua } \\
\text { associação } \\
\text { com os } \\
\text { fatores } \\
\text { biossociais e } \\
\text { de trabalho. }\end{array}$ & $\begin{array}{c}\text { A associação dos } \\
\text { construtos com as } \\
\text { variáveis } \\
\text { qualitativas foi } \\
\text { realizada com o } \\
\text { teste do Qui- } \\
\text { Quadrado e para } \\
\text { as variáveis } \\
\text { quantitativas, o } \\
\text { teste-t ou Análise } \\
\text { de Variância }\end{array}$ \\
\hline
\end{tabular}




\begin{tabular}{|c|c|c|c|c|c|c|}
\hline 3 & $\begin{array}{l}\text { Um hospital } \\
\text { geral com fins } \\
\text { lucrativos, } \\
\text { localizado na } \\
\text { Serra } \\
\text { Gaúcha }\end{array}$ & $\begin{array}{l}\text { Variáveis } \\
\text { demográficas e } \\
\text { ocupacionais e } \\
\text { Malasch Burnout } \\
\text { Inventory (MBI) }\end{array}$ & $\begin{array}{c}164 \\
\text { trabalhadores } \\
\text { de } \\
\text { enfermagem }\end{array}$ & $\begin{array}{l}\text { Transversal, } \\
\text { contemplando } \\
\text { uma abordagem } \\
\text { quantitativa }\end{array}$ & $\begin{array}{c}\text { Fatores } \\
\text { ocupacionais } \\
\text { e os três } \\
\text { componentes } \\
\text { da Síndrome } \\
\text { de Burnout }\end{array}$ & $\begin{array}{c}\text { Estatística } \\
\text { descritiva, para } \\
\text { análise da } \\
\text { associação de } \\
\text { variáveis utilizou- } \\
\text { se o teste T de } \\
\text { Student }\end{array}$ \\
\hline 4 & $\begin{array}{l}\text { Um hospital } \\
\text { geral do nível } \\
\text { terciário de } \\
\text { atenção do } \\
\text { Sistema } \\
\text { Único de } \\
\text { Saúde, na } \\
\text { cidade do } \\
\text { Recife }\end{array}$ & $\begin{array}{l}\text { Aspectos sócio- } \\
\text { demográficos, } \\
\text { formação } \\
\text { profissional e } \\
\text { condições de } \\
\text { trabalho, } \\
\text { Maslach Burnout } \\
\text { Inventory (MBI) }\end{array}$ & $\begin{array}{l}63 \\
\text { enfermeiros }\end{array}$ & $\begin{array}{l}\text { Descritivo, de } \\
\text { corte transversal, } \\
\text { censitário, de } \\
\text { outubro a } \\
\text { novembro de } \\
2009\end{array}$ & $\begin{array}{c}\text { Testou-se a } \\
\text { associação } \\
\text { entre as } \\
\text { variáveis } \\
\text { sócio- } \\
\text { demográficas, } \\
\text { da formação } \\
\text { profissional e } \\
\text { do trabalho e } \\
\text { as três } \\
\text { dimensões do } \\
\text { burnout. }\end{array}$ & $\begin{array}{l}\text { A existência de } \\
\text { diferenças } \\
\text { significativas foi } \\
\text { avaliada usando o } \\
\text { qui-quadrado }\end{array}$ \\
\hline 5 & $\begin{array}{l}\text { Um hospital } \\
\text { geral do nível } \\
\text { terciário de } \\
\text { atenção do } \\
\text { Sistema } \\
\text { Único de } \\
\text { Saúde, na } \\
\text { cidade do } \\
\text { Recife }\end{array}$ & $\begin{array}{l}\text { Aspectos sócio- } \\
\text { demográficos, } \\
\text { formação } \\
\text { profissional e } \\
\text { condições de } \\
\text { trabalho, } \\
\text { Maslach Burnout } \\
\text { Inventory (MBI) }\end{array}$ & 158 médicos & $\begin{array}{l}\text { Transversal, } \\
\text { censitário, } \\
\text { realizado de } \\
\text { outubro a } \\
\text { novembro de } \\
2009\end{array}$ & $\begin{array}{c}\text { Associação } \\
\text { entre as } \\
\text { variáveis } \\
\text { sociodemográ } \\
\text { ficas, da } \\
\text { formação } \\
\text { profissional e } \\
\text { do trabalho e } \\
\text { a frequência } \\
\text { do } \\
6 \text { e de cada } \\
\text { uma das três } \\
\text { dimensões }\end{array}$ & $\begin{array}{l}\text { Diferenças } \\
\text { significativas foram } \\
\text { avaliadas usando } \\
\text { o qui-quadrado e o } \\
\text { teste exato de } \\
\text { Fisher, quando } \\
\text { necessário }\end{array}$ \\
\hline 6 & $\begin{array}{l}\text { Rede de } \\
\text { Atenção } \\
\text { Primária à } \\
\text { Saúde } \\
\text { (REAP) do } \\
\text { município de } \\
\text { Aracaju/SE. }\end{array}$ & $\begin{array}{c}\text { Características } \\
\text { sociodemográfic } \\
\text { as e de saúde } \\
\text { dos profissionais, } \\
\text { Maslach Burnout } \\
\text { Inventory - } \\
\text { Human Services } \\
\text { Survey (MBI - } \\
\text { HSS) }\end{array}$ & $\begin{array}{l}198 \\
\text { profissionais } \\
\text { de nível } \\
\text { superior }\end{array}$ & $\begin{array}{c}\text { Transversal } \\
\text { realizado no } \\
\text { período de junho } \\
\text { a agosto de } 2012\end{array}$ & $\begin{array}{c}\text { Característica } \\
\text { s } \\
\text { sociodemográ } \\
\text { ficas e de } \\
\text { saúde dos } \\
\text { profissionais, } \\
\text { também as } \\
\text { característica } \\
\text { s econômicas } \\
\text { e } \\
\text { relacionadas } \\
\text { à ocupação, } \\
\text { as } \\
\text { propriedades } \\
\text { psicométricas } \\
\text { do MBI para }\end{array}$ & $\begin{array}{l}\text { Frequências } \\
\text { simples e relativas, } \\
\text { foi aplicado o teste } \\
\text { Quiquadrado de } \\
\text { Pearson, ANOVA } \\
\text { (Análise de } \\
\text { variância) com um } \\
\text { fator, seguido do } \\
\text { pós-teste de } \\
\text { Tukey para as } \\
\text { variáveis }\end{array}$ \\
\hline 7 & $\begin{array}{c}\text { Atenção } \\
\text { primária a } \\
\text { saúde de três } \\
\text { munícipios de } \\
\text { pequeno } \\
\text { porte de } \\
\text { Minas Gerais }\end{array}$ & $\begin{array}{c}\text { Aspectos } \\
\text { individuais, } \\
\text { sociodemográfic } \\
\text { os, área de } \\
\text { cobertura da } \\
\text { equipe, Maslach } \\
\text { Burnout } \\
\text { Inventory (MBI) }\end{array}$ & $\begin{array}{l}107 \\
\text { profissionais } \\
\text { das APS }\end{array}$ & $\begin{array}{c}\text { Caráter } \\
\text { exploratório, } \\
\text { possuindo } \\
\text { objetivos } \\
\text { descritivos e } \\
\text { correlacionais }\end{array}$ & $\begin{array}{c}\text { O estudo } \\
\text { analisa a } \\
\text { associação } \\
\text { por regressão } \\
\text { logística entre } \\
\text { esgotamento } \\
\text { profissional, } \\
\text { aspectos } \\
\text { socioeconômi } \\
\text { cos, }\end{array}$ & $\begin{array}{c}\text { Análises } \\
\text { inferenciais Odds } \\
\text { Ratio (OR), } \\
\text { QuiQuadrado de } \\
\text { Pearson e teste } \\
\text { exato de Fisher e } \\
\text { o modelo de } \\
\text { regressão logística } \\
\text { backward stepwise }\end{array}$ \\
\hline
\end{tabular}




\begin{tabular}{|c|c|c|c|c|c|c|}
\hline & & & & & $\begin{array}{c}\text { demográficos } \\
\text { e aspectos do } \\
\text { trabalho. }\end{array}$ & \\
\hline 8 & $\begin{array}{c}\text { Instituições } \\
\text { hospitalares } \\
\text { em Porto } \\
\text { Alegre (Brasil) } \\
\text { e no Porto } \\
\text { (Portugal). }\end{array}$ & $\begin{array}{c}\text { Variáveis } \\
\text { sociodemográfic } \\
\text { as e laborais, } \\
\text { Maslach Burnout } \\
\text { Inventory - } \\
\text { Human Services } \\
\text { Survey (MBI - } \\
\text { HSS) e o } \\
\text { Questionário de } \\
\text { Satisfação no } \\
\text { Trabalho S20/23 }\end{array}$ & $\begin{array}{c}224 \\
\text { profissionais } \\
\text { de saúde: } 112 \\
\text { de brasileiros } \\
\text { (Porto Alegre) } \\
\text { e } 112 \\
\text { portugueses } \\
\text { (Porto) }\end{array}$ & $\begin{array}{l}\text { Estudo } \\
\text { transcultural }\end{array}$ & $\begin{array}{c}\text { As dimensões } \\
\text { de burnout e } \\
\text { variáveis } \\
\text { sociodemográ } \\
\text { ficas, laborais } \\
\text { e } \\
\text { psicossociais } \\
\text { nos } \\
\text { profissionais } \\
\text { de saúde } \\
\text { brasileiros e } \\
\text { portugueses. }\end{array}$ & $\begin{array}{l}\text { Prova t de student } \\
\text { para variáveis } \\
\text { qualitativas e } \\
\text { correlação de } \\
\text { Pearson para as } \\
\text { quantitativas }\end{array}$ \\
\hline 9 & $\begin{array}{l}\text { Escolas da } \\
\text { jurisdição da } \\
\text { Superintendê } \\
\text { ncia Estadual } \\
\text { de Ensino } \\
\text { (SEE) de } \\
\text { Januária, em } \\
\text { Minas Gerais }\end{array}$ & $\begin{array}{c}\text { Características } \\
\text { psicofísicas em } \\
\text { relação ao } \\
\text { trabalho, } \\
\text { Questionário } \\
\text { Preliminar de } \\
\text { Identificação do } \\
\text { Burnout, } \\
\text { Síndrome do } \\
\text { Esgotamento } \\
\text { Profissional } \\
\text { (SEP) e Maslach } \\
\text { Burnout } \\
\text { Inventory (MBI- } \\
\text { ED) }\end{array}$ & $\begin{array}{l}462 \\
\text { professores }\end{array}$ & $\begin{array}{l}\text { Descritivo, } \\
\text { quantitativo e de } \\
\text { corte transversal }\end{array}$ & $\begin{array}{c}\text { Associação } \\
\text { das } \\
\text { característica } \\
\text { s psicofísicas } \\
\text { em relação ao } \\
\text { trabalho com } \\
\text { Burnout }\end{array}$ & $\begin{array}{c}\text { Estatística } \\
\text { descritiva, teste } \\
\text { qui-quadrado }\end{array}$ \\
\hline 10 & $\begin{array}{c}\text { Setores de } \\
\text { terapia } \\
\text { intensiva de } \\
\text { hospital de } \\
\text { grande porte, } \\
\text { no município } \\
\text { do Rio de } \\
\text { Janeiro }\end{array}$ & $\begin{array}{c}\text { Aspectos } \\
\text { laborais; } \\
\text { sociodemográfic } \\
\text { os; saúde física e } \\
\text { emocional; } \\
\text { antecedentes e } \\
\text { hábitos de vida; } \\
\text { e saúde e bem- } \\
\text { estar Maslach } \\
\text { Burnout } \\
\text { Inventory (MBI) }\end{array}$ & $\begin{array}{c}85 \\
\text { profissionais } \\
\text { de } \\
\text { enfermagem }\end{array}$ & $\begin{array}{l}\text { Epidemiológico } \\
\text { observacional, } \\
\text { descritivo } \\
\text { seccional. }\end{array}$ & $\begin{array}{c}\text { As dimensões } \\
\text { da síndrome } \\
\text { de burnout e } \\
\text { associadas } \\
\text { com as } \\
\text { variáveis } \\
\text { relacionadas } \\
\text { ao trabalho } \\
\text { em UTI }\end{array}$ & $\begin{array}{l}\text { Análise estatística } \\
\text { descritiva }\end{array}$ \\
\hline 11 & $\begin{array}{l}\text { Unidades de } \\
\text { terapia } \\
\text { intensiva } \\
\text { adulto de } \\
\text { Salvador-BA }\end{array}$ & $\begin{array}{c}\text { Características } \\
\text { sóciodemográfic } \\
\text { as, } \\
\text { Maslach Burnout } \\
\text { Inventory (MBI) }\end{array}$ & $\begin{array}{l}297 \text { médicos } \\
\text { plantonistas }\end{array}$ & $\begin{array}{l}\text { Descritivo de } \\
\text { corte transversal }\end{array}$ & $\begin{array}{l}\text { Variáveis } \\
\text { sócio- } \\
\text { demográficas } \\
\text { e condições } \\
\text { de trabalho } \\
\text { com o } \\
\text { resultado do } \\
\text { MBI }\end{array}$ & $\begin{array}{c}\text { Estatística } \\
\text { descritiva, análise } \\
\text { de associação } \\
\text { utilizando-se a } \\
\text { Razão de } \\
\text { Prevalência (RP) }\end{array}$ \\
\hline
\end{tabular}

Fonte: Elaborada pelas autoras.

Com a leitura dos resultados das pesquisas selecionadas nesta revisão, observa-se que diversos fatores estão associados a síndrome de burnout. O estudo 
1, realizado com professores de escolas públicas e privadas em Porto Alegre-RS, concluiu que mulheres, sem companheiro fixo, sem filhos, com idade mais elevada, que possuem maior carga horária, que atendem maior número de alunos e trabalham em escolas públicas apresentam maior risco de desenvolvimento de burnout (CARLOTTO, 2010). No estudo 2 com profissionais de enfermagem de um hospital público em São Paulo-SP, sujeitos em níveis elevados de estresse verificouse a presença de burnout, sugerindo que a maior parte dos participantes da pesquisa percebem os estressores no trabalho como desafio. Outro achado de destaque se refere aos fatores horas de sono efetivamente dormidas, presença do companheiro e gostar do trabalho como variáveis que contribuíram positivamente para o enfrentamento do estresse e prevenção de burnout neste estudo (ANDOLHE, BARBOSA, OLIVEIRA, COSTA, PADILHA, 2015).

No 3 realizado em um hospital geral com fins lucrativos na Serra Gaúcha, com profissionais de enfermagem os resultados apontam que os componentes de Burnout apresentaram associações estatísticas significativas $(p<0,05)$ com diversas características ocupacionais, tais como a sobrecarga de trabalho, falta de motivação para o trabalho, conflito de valores pessoais com institucionais, falta de possibilidades de recompensas, ter a mesma função em instituições diferentes, e dificuldade em conciliar os empregos (MENEGHINI, PAZ, LAUTERT, 2011). No estudo 4 realizado com enfermeiros de um hospital público em Recife, os resultados mostraram associação entre alto nível de exaustão emocional (EE) e realizar frequentemente/sempre tarefas com muita rapidez $(p=0,039)$ e receber salário incompatível com o esforço empregado $(p=0,016)$; altos níveis de despersonalização (DP) e ter até cinco anos de profissão $(p=0,010)$ e efetuar frequentemente/sempre tarefas com muita rapidez ( $p=0,009)$ (GALINDO, FELICIANO, LIMA, SOUZA, 2012). No 5 realizado com médicos de um hospital público em Recife os resultados mostraram associação com alto nível de EE e realizar "frequentemente/sempre" tarefas com muita rapidez e "nunca/às vezes" ter tempo suficiente; alto nível de DP e ter até dez anos de profissão e efetuar "frequentemente/sempre" tarefas com muita rapidez; baixo nível de realização profissional e gênero feminino e "nunca/às vezes" ter tempo suficiente; burnout e executar "frequentemente/ sempre" tarefas com muita rapidez, "nunca/às vezes" dispor de tempo suficiente, ser do gênero masculino e não 
ter expectativa de ascensão profissional (LIMA, SOUZA, GALINDO, FELICIANO, 2013).

No estudo 6 com profissionais de nível superior da rede de atenção primária em Aracaju-SE os fatores associados foram idade mais jovem, carga horária de trabalho excessiva e insatisfação profissional (SILVA et al., 2015). No 7 realizado com profissionais da saúde na atenção básica em Minas Gerais-MG, os fatores foram possuir idade inferior à mediana da população (> 29,5 anos) e fazer uso de medicamentos "calmantes, tranquilizantes e remédios para dormir" (MARTINS et al., 2014). Já no estudo 8, com profissionais de saúde em instituições hospitalares em Porto Alegre no Brasil e no Porto em Portugal, encontraram associação entre exaustão emocional e a satisfação com o ambiente físico de trabalho, indicando maior desgaste quando mais insatisfeitos com as condições de trabalho. Também houve associação os solteiros/separados/viúvos e profissionais sem filhos evidenciaram índices mais elevados de exaustão emocional, verificaram-se diferenças estatisticamente significativas entre Brasil e Portugal, os profissionais portugueses que pensavam em mudar de profissão apresentaram médias mais elevadas de exaustão emocional e despersonalização e os profissionais brasileiros menor realização profissional (DIAS, QUEIRÓS, CARLOTTO, 2010).

No estudo 9 realizado com professores da cidade de Januária-MG burnout esteve associada à baixa remuneração, à dedicação com a carreira docente e com o tempo de trabalho de um a 11 ou anos ou mais (SILVA et al., 2017). No estudo 10 realizado com profissionais de enfermagem que trabalham em UTI's num hospital geral do Rio de Janeiro-RJ, ter cursado ensino superior apresentou associação com a síndrome, assim como as variáveis laborais: categoria profissional enfermeiro, e sentir-se estressado no trabalho (SOARES, 2018). No $11 \mathrm{com}$ médicos plantonistas de UTI's em Salvador-BA verificou-se que burnout está associado aos plantonistas mais jovens, com elevada carga de trabalho e sem especialização em medicina intensiva (BARROS, TIRONI, NASCIMENTO SOBRINHO, 2008).

Diante os achados, é possível relatar que burnout está diretamente associada a variáveis pessoais como sexo, idade, relação conjugal e filhos demonstrando que os trabalhadores precisam antes de tudo conhecer a síndrome para que possa encontrar mecanismos próprios de defesa, mas percebesse que burnout também 
está intimamente associada com as condições de trabalho, salários, carga horária, características profissionais e com as organizações, o que convida aos gestores além de conhecer as condições de saúde dos trabalhadores, buscar maneiras de favorecer as condições de trabalho em cada profissão, através de melhoria das políticas públicas já existentes e na criação de novas políticas.

\section{CONCLUSÃO}

Burnout está associado a diversos fatores individuais, sociais, psicológicos e ambientais no trabalho, esta informação trata-se de um alerta tanto para os trabalhadores, como para os gestores, sejam eles de instituições públicas ou privadas. Existe uma via de mão dupla, pois por parte os trabalhadores devem possuir mecanismos próprios de defesa e as organizações devem pautar-se das melhorias e novas políticas públicas em busca da garantia da prestação de serviço com qualidade. Apesar desta importante informação no âmbito nacional considerase esta revisão limitada pois não abrange realidades internacionais, estudos comparativos entre os diferentes países podem ser uma maneira de encontrar diferenças culturais nas organizações que sejam passiveis de adaptações para cada realidade territorial em busca da prevenção e combate ao burnout.

Sugere-se estudos futuros mais abrangentes, que envolvam outros aspectos além dos sociodemográficos e laborais que possam estar associados a síndrome, como o estresse, a depressão, a capacidade para o trabalho, absenteísmo e o empoderamento psicológico, sugere- se também estudos comparativos com burnout entre instituições privadas e públicas. 


\section{REFERÊNCIAS BIBLIOGRÁFICAS}

ANDOLHE, R.; BARBOSA, R. L.; OLIVEIRA, E. M.; COSTA, A. L. S.; PADILHA, K. G. Estresse, coping e burnout da Equipe de Enfermagem de Unidades de Terapia Intensiva: fatores associados. Rev Esc Enferm USP, n. 49, v. esp., p. 58-64, 2015.

BARROS, D.S.; TIRONI, M. O. S.; NASCIMENTO SOBRINHO, C. L.; NEVES, F. S.; BITENCOURT, A. G. V. ALMEIDA, A. M. et al. Médicos plantonistas de unidade de terapia intensiva: perfil sócio-demográfico, condições de trabalho e fatores associados à síndrome de burnout. Rev Bras Ter Intensiva.; n.20, v.3, p.235-240, 2008.

CARLOTTO, M. S. Síndrome de Burnout: 0 estresse ocupacional do professor. Canoas, RS: Editora Ulbra. 2010.

CARLOTTO, M. S. Síndrome de Burnout em Professores: Prevalência e Fatores Associados Psic.: Teor. e Pesq., Brasília, Out-Dez, v. 27, n. 4, p. 403-410, 2011.

DIAS, S.; QUEIRÓS, C.; CARLOTTO, M. S. Síndrome de burnout e fatores associados em profissionais da área da saúde: um estudo comparativo entre Brasil e Portugal. Aletheia, n.32, p.4-21, maio/ago. 2010.

FELICIANO, K.V.O.; LIMA, R. A. S.; SOUZA, A. I.; GALINDO, R. H. Síndrome de burnout entre enfermeiros de um hospital geral da cidade do Recife, Rev Esc Enferm USP; n.46, v.2, p.420427, 2012.

GARCIA, L.P.; BENEVIDES-PEREIRA, A.M.T. Investigando o Burnout em Professores universitários. Interação Psi, n.1, p.76-89, 2003.

GIL-MONTE, P. R. El sindrome de quemarse por el trabajo (Síndrome de Burnout) en profesionales de enfermería. Revista Eletrônica InterAção Psy, v. 1, n. 1, p.: 19-33. 2003.

GIL-MONTE, P. R. El síndrome de quemarse por el trabajo (burnout) como fenómeno transcultural. Información Psicológica, n.91, p. 4-11, 2008.

LIMA, R. A. S.; SOUZA, A. I.; GALINDO, R. H.; FELICIANO, K.V.O. Vulnerabilidade ao burnout entre médicos de hospital público do Recife. Ciência \& Saúde Coletiva, n.18 v.4, p.1051-1058, 2013.

MARTINS, L. F.; LAPORT, T. J.; MENEZES, V. P.; MEDEIROS, P. B.; RONZANI, T. M. Esgotamento entre profissionais da atenção Primária à Saúde. Ciência \& Saúde Coletiva, n.19, v.12, p.4939-4750, 2014.

MASLACH, C. Burn-Out: the loss of human caring. Human Behavior, v. 5, p.16-22, 1976.

MASLACH, C. Comprendiendo el burnout. Revista Ciencia \& Trabajo, n. 11, v.32, p. 37- 43, 2009.

MASLACH, C.; JACKSON, S. E. Maslach burnout Inventory: the measurement of experienced burnout. Journal of Ocuppational Behavior, n.2, v.1, p. 99-113. Palo Alto: Consulting Psychologist Press, 1981.

MASLACH, C.; LEITER, M. P. Early predictors of job burnout and engagement. Journal of Applied Psychology, n.93, p.498-512, 2008.

MASLACH, C.; SHAUFELI, W. B.; LEITER, M. P. Job burnout. Annual Review of Psychology, 
n. 52, p. 397-422, 2001.

MELNYK, B.M.; FINEOUT-OVERHOLT E. Making the case for evidence-based practice. In: Melnyk BM, Fineout-Overholt E. Evidence based practice in nursing \& healthcare. A guide to best practice. Philadelphia: Lippincot Williams \& Wilkins, p.3-24, 2005.

MENDES, K. D. S.; SILVEIRA, R. C. C. P.; GALVÃO, C. M. Revisão integrativa: método de pesquisa para a incorporação de evidências na saúde e na enfermagem. Texto Contexto Enferm, Florianópolis, v.17, n. 4, p. 758-764, 2008.

MENEGHINI, F.; PAZ, A. A.; LAUTERT, L. Fatores ocupacionais associados aos componentes da síndrome de burnout em trabalhadores de enfermagem. Texto Contexto Enferm, Florianópolis, Abr-Jun; n.20, v.2, p. 225-33, 2011.

MOHER, D.; LIBERATI, A.; TETZLAFF, J.; ALTMAN, D.G. PRISMA Group. Preferred reporting items for systematic reviews and meta-analyses: the PRISMA statement. Ann Intern Med, v. 151, n. 4, p. 264-269. PubMed PMID: 19622511, 2009.

SÁ, A. M. S.; MARTINS-SILVA, P. O.; FUNCHAL, B. Burnout: o impacto da satisfação no trabalho em profissionais de enfermagem. Psicologia \& Sociedade, n.26 v.3, p.664-674., 2014.

SALVIANO, I. C. B. Síndrome de burnout em profissionais de enfermagem em unidade de terapia intensiva. Revista Saúde e Desenvolvimento, n.10, v.5, 2016.

SILVA, A. F.; MAIA, M. F. M.; LIMA, C. A. G.; GUEDESA, I. T.; PEDREIRA, K. C.; SILVA, D. A. S.; PETROSKI, E. L. Fatores que prevalecem ao esgotamento profissional em professores. Cad. Bras. Ter. Ocup., São Carlos, v. 25, n. 2, p. 333-339, 2017.

SILVA, S. C. P. S.; NUNES, M. A. P.; SANTANA, V. R.; REIS, F. P.; NETO, J. M.; LIMA, S. O. A síndrome de burnout em profissionais da rede de atenção Primária à Saúde de Aracaju, Brasil. Ciência \& Saúde Coletiva, n.20, v.10, p.3011-3020, 2015.

SOARES, R. S. Burnout e fatores associados entre profissionais de enfermagem de hospital municipal no Rio de Janeiro. (Dissertação de Mestrado), Universidade Federal Fluminense, 2018.

TRIGO, T. R.; TENG, C. T.; HALLAK, J. E. C. Síndrome de burnout ou estafa profissional e os transtornos psiquiátricos. Rev. psiquiatr. clín. [online]., v.34, n.5, p.223-233, 2007. 